\title{
Adhesion-peptide conjugates of thermo-responsive polymers co-electrospun into fibrous scaffolds enable growth and enzyme-free recovery of quiescent human Corneal Stromal Cells (hCSCs).
}

\author{
Floor A. A. Ruiter ${ }^{a}$, Laura E. Sidney ${ }^{b}$, Kristi L. Kiick ${ }^{c}$, Joel I. Segal ${ }^{d}$, Cameron Alexander, and Felicity R. A. J. Rose ${ }^{a}$ \\ a School of Pharmacy, University of Nottingham, UK, f.ruiter@maastrichtuniversity.nl, felicity.rose@nottingham.ac.uk, \\ cameron.alexander@nottingham.ac.uk \\ b Division of Clinical Neuroscience, University of Nottingham, UK, laura.sidney@nottingham.sc.uk \\ c Department of Material Science and Engineering, University of Delaware, USA, kiick@udel.edu \\ ${ }^{d}$ Faculty of Engineering, University of Nottingham, UK, joel.segal@nottingham.ac.uk \\ FAA Ruiter is now working at Maastricht University in the MERLN institute.
}

Human corneal stromal cells (hCSCs) are in high demand for ocular repair following injury or disease but differentiate to an undesirable activated fibroblastic phenotype when cultured by conventional methods. Here we report a new peptide-functionalised thermo-responsive electrospun cell culture scaffold that supports rapid expansion, phenotypic expression and enzyme-free passaging of quiescent hCSCs for potential ocular repair applications.

Current methods of adherent mammalian cell expansion for tissue engineering and regenerative medicine applications rely usually on the use of 2D culture platforms, foetal bovine serum containing media, and enzymatic digestion for cell recovery. However, 2D culture of primary cells can result in undesired de-differentiation, ${ }^{1-3}$ due to the lack of similarities to the natural extracellular matrix (ECM) environment, and enzyme passaging can significantly reduce cell quality, ${ }^{4-6}$ as a result of the destruction of important cellsurface proteins. In recent years, thermo-responsive surfaces 7,8 have been used as supports for mammalian cell culture, as their changes in physicochemical properties at upper or lower critical solution temperatures (UCST, LCST) can facilitate cell detachment without the need for enzymatic passaging. ${ }^{9-13}$ However, while the polymer phase transitions result in measurable "hydrophilic-tohydrophobic" behaviour changes, these differences are often only moderate in terms of their effects on cell adhesion. Accordingly, there is a need to generate materials, which provide selective functionality for specific cells to attach, while retaining their ability to release cells via a mild temperature change at the end of the cell culture and expansion period.

Here we report the development of a new thermo-responsive adhesion peptide-functionalised (GGG-YIGSR) fibre-scaffold based on co-electrospun poly(DL-lactide) (PLA) and poly(di(ethylene glycol) methyl ether methacrylate)-co-poly(di(ethylene-glycol) carboxylate ester ethyl thiol) (PDEGMA/PDEGSH, Fig. 1A) for enzyme-free 3D mammalian cell culture. We have exemplified this concept via the growth and recovery of human corneal stromal cells (hCSCs) in non-serum containing media. These cells were chosen as hCSCs display a well characterised phenotypic change during conventional in vitro culture from a keratocyte phenotype (quiescent, $\mathrm{CD}^{4} 4^{+}, \mathrm{ALDH}^{+}$) to a mesenchymal stem cell/fibroblast/myofibroblast phenotype (proliferative, $\mathrm{CD} 105^{+}, \alpha-\mathrm{SMA}+{ }^{+}{ }^{14} \mathrm{The}^{\circ}$ laminin sequence YIGSR was selected for this study as previous literature has shown that interaction with this peptide sequence supports hCSCs attachment and the maintenance of a quiescent keratocyte phenotype. ${ }^{15}$

Co-spinning PLA with thermo-responsive polymers of PDEGMA and a side-chain thiol-functionalised PDEGSH generated fibrous scaffolds with 'click' handles for peptide coupling. The subsequent conjugation chemistries were carried out by reacting norbornene-fuctionalised peptides (Nor-GGG-YIGSR, Fig. 1C) with the side-chain thiols via a UV-mediated thiol-ene reaction (Fig. 1B). Attachment of the peptides on the scaffolds was confirmed by fluorescence labelling, ToF-SIMS and XPS analysis. The resulting bioconjugate scaffolds were assessed for their ability to support hCSC culture by cell adhesion, proliferation and immunocytochemistry assays. The phenotypic profiling of hCSCs after thermo-responsive passaging was evaluated by flow cytometry analysis of key cell surface markers. The combined assay data indicated that the expansion of hCSCs could be conducted with high yield and retention of a therapeutically desirable phenotype without using expensive and potentially cell-damaging enzymatic methods. The ability to culture, expand and recover therapeutically relevant cell types makes these scaffolds a promising new class of materials for application in many areas of regenerative medicine, where cells are destined for the clinic.

\section{Polymer synthesis}

The co-polymers PDEGMA/PDEGSH in different ratios (100:0, 98:2, 97:3, 96:4, and 90:10, PDEGMA to PDEGSH respectively) were synthesised by a two-step route (scheme. Fig $1 \mathrm{~A}$ ) and structures were confirmed by 2D-NMR analysis (Fig. S1-S18) with the 
A

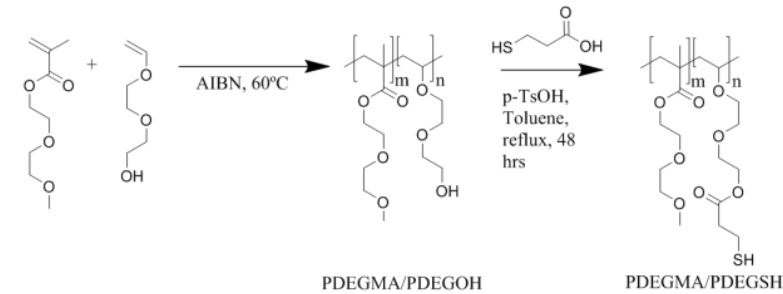

B

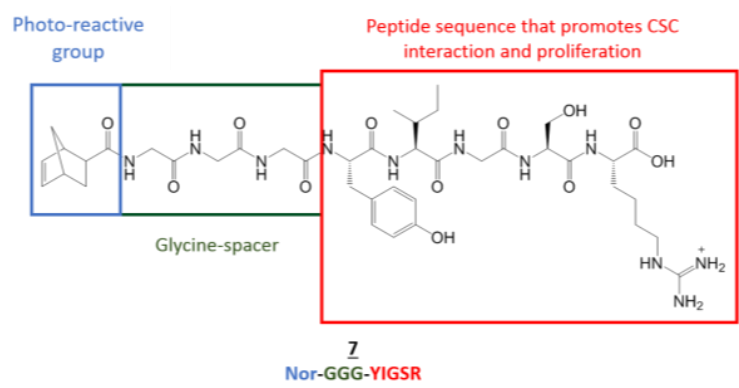

C
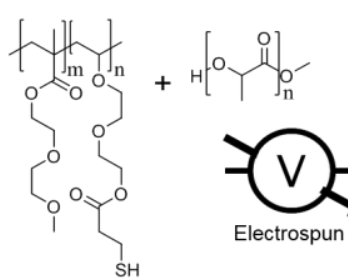

Electrospun

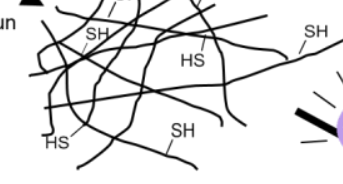

Peptide

D

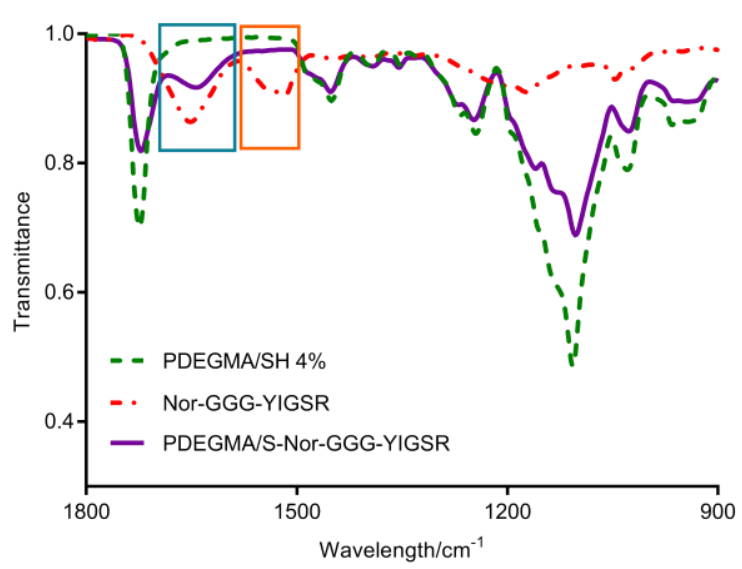

E

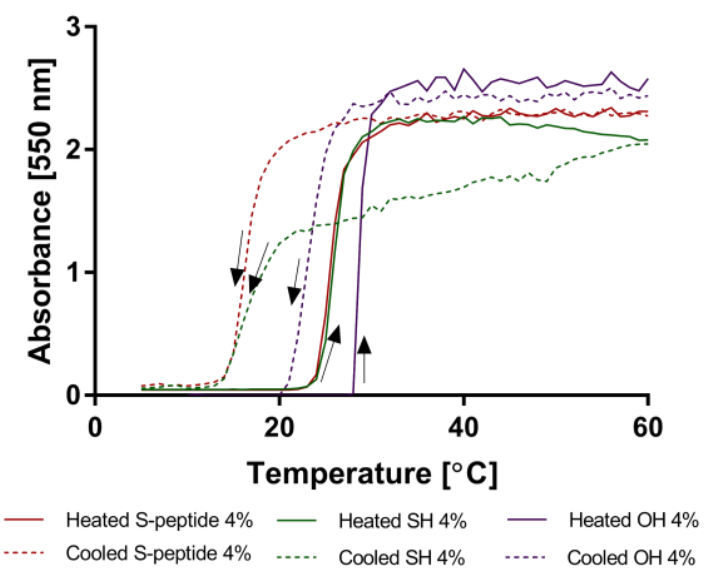

Figure 1. Schematics of A) the PDEGMA/PDEGSH synthesis, B) the formation of polymer-peptide derivative electrospun scaffolds, C) the chemical structure of the synthesised Nor-GGG-YIGSR peptide sequence. Nor (blue block) is the norbornene acid photo-reactive group, GGG (green block) is used as a spacer and YIGSR (red block) sequence previously identified to promote hCSCs proliferation. E) Cloud point hysteresis of PDEGMA, PDEGMA/PDEGOH, PDEGMA/PDEGSH and PDen when poly F) FT-IR spectra from pure Nor-GGG-YIGSR (red) PDEGMA/PDEGSH (green) and peptide functionalised PDEGMA thiol-ene chemistry (purple). The double bond from the norbornene acid disappeared and the amino groups of the peptide appeared on the FT-IR of the functionalised polymer-peptide.

disappearance of the $\mathrm{C}_{2}{ }_{2} \mathrm{OH}$ signal ( $\mathrm{H}^{1}-\mathrm{NMR} ; 3.7-3.8 \mathrm{ppm}, \mathrm{t}, 2 \mathrm{H}$ and $\mathrm{C}^{13}-\mathrm{NMR} ; 61 \mathrm{ppm}$ ) and the appearance of the $\mathrm{CH}_{2} \mathrm{SH}$ peaks ( $\mathrm{H}^{1}-\mathrm{NMR} ; 2.9 \mathrm{ppm}, \mathrm{t}, 2 \mathrm{H}$ and $\mathrm{C}^{13}-\mathrm{NMR} ; 34 \mathrm{ppm}$ ) in the $\mathrm{H}^{1}$ and $\mathrm{C}^{13}-\mathrm{NMR}$ of the end product PDEGMA/PDEGSH. Full materials, methods and characterisation can be found in the supplementary section 1, Fig. S1-18 for NMR and Tab. S3 for GPC. Percentages of free thiol in the co-polymers were confirmed by the Ellman's assay (Tab. 1). The phase transition temperatures $\left(T_{t}\right)$ of the polymers were estimated by cloud point measurements (Fig. 1E, S19 and Tab. S4). The norbornene functionalised peptide GGGYIGSR was synthesised on a rink amide resin, purified by HPLC and its structure verified by electrospray ionisation mass 
Table 1. Percentage of detected free thiol groups in the synthesised PDEGMA/PDEGSH polymers. Detection and free thiol group concentration estimation were carried out by Ellman's assay by detecting the absorbance of the Ellman's assay reaction product. $C_{\text {polymer }}=$ Concentration of polymer in PBS, Abs= Absorbance at $412 \mathrm{~nm}, \mathrm{C}_{\text {thiols }}=$ concentration of thiols calculated from standard curve, and conv.=conversion.

\begin{tabular}{|c|c|c|c|c|}
\hline \multicolumn{5}{|c|}{ Percentage of free thiols in co-polymers } \\
\hline$\% \mathrm{OH}$ & C $_{\text {polymer }}$ & Abs & $\mathrm{C}_{\text {thiols }}$ & $\%$ \\
\hline & {$[\mathrm{mmol} / \mathrm{ml}]$} & & {$[\mathrm{mmol} / \mathrm{ml}]$} & SH \\
\hline 2 & $70 * 10^{-4}$ & 0.0877 & $1.2 * 10^{-4}$ & 1.7 \\
\hline 3 & $70 * 10^{-4}$ & 0.1249 & $1.5 * 10^{-4}$ & 2.2 \\
\hline 4 & $70 * 10^{-4}$ & 0.2483 & $2.6 * 10^{-4}$ & 3.7 \\
\hline 10 & $70 * 10^{-4}$ & 0.7328 & $6.8 * 10^{-4}$ & 9.7 \\
\hline
\end{tabular}

Percentage of free thiols after thiol-ene chemistry

\begin{tabular}{|c|c|c|c|c|c|}
\hline $\begin{array}{l}\mathrm{UV}_{\text {time }} \\
\text { [mins] }\end{array}$ & $\begin{array}{l}\text { C } \text { polymer } \\
{[\mathrm{mmol} / \mathrm{ml}]}\end{array}$ & Abs & $\begin{array}{c}\mathrm{C}_{\text {thiols }} \\
{[\mathrm{mmol} / \mathrm{ml}]}\end{array}$ & $\begin{array}{c}\% \\
\text { SH }\end{array}$ & $\%$ conv. \\
\hline 0 & $70 * 10^{-4}$ & 0.2483 & $2.6 * 10^{-4}$ & 3.7 & 0 \\
\hline 5 & $19 * 10^{-4}$ & 0.0300 & $6.8 * 10^{-4}$ & 2.0 & 46 \\
\hline 10 & $19 * 10^{-4}$ & 0.0295 & $6.8 * 10^{-4}$ & 2.0 & 46 \\
\hline 15 & $70 * 10^{-4}$ & 0.0537 & $0.9 * 10^{-4}$ & 1.3 & 65 \\
\hline
\end{tabular}

surface of the scaffolds (Fig. $\$ 22$ and Tab. S6). The distributions of the free thiols and peptides on the scaffolds surface were investigated further by ToF-SIMS analysis. Mass spectrometry peaks of the ion fragments were identified and confirmed through literature (Tab. S4). ${ }^{17-20}$ The ion fragment $\mathrm{CH}_{3} \mathrm{O}^{-}$attributed to the underivatised PDEGMA was present on the surface, and a decrease in peak intensity of $\mathrm{CH}_{3} \mathrm{O}^{-}$was observed for all the scaffolds containing PDEGMA/PDEGSH co-polymer (Fig. 2A). ToF-SIMS peak distribution images indicated that $\mathrm{SH}$ groups were in regions corresponding to the fibre positions on the substrate (Fig. $2 \mathrm{C}$ and Fig. S22), confirming an even distribution of the free thiols on the fibrous surface. A decrease in $\mathrm{S}^{-}$and $\mathrm{SH}^{-}$absorptions were detected for the thiol-ene derivatised scaffolds (Fig. 2A). The CNO- peak of the peptide amino-groups were observed for all scaffolds incubated with peptide (Fig. 2A). Significantly higher intensity was detected for the scaffold 3S-P, with a decrease in CNOintensity being observed for 4 and 10 S-P (Fig. 2A).

Nor-GGG-YIGSR peptide positive ion fragment signals were identified and were corroborated to literature 21,22 (see fragment structures of identified signals in Fig. S23). Peptide fragments were detected for all scaffolds, including the 0SH scaffolds (Fig. 2B). This suggested that non-specific electrostatic binding of the peptide occurred with the surface of the scaffolds. The distribution images of the signal, an even distribution of peptide fragment peaks was observed on the $0 \%$ thiol scaffold without a defined fibre morphology (Fig. 2C). However, in case of the peptide-derivatised scaffolds, more defined fibre morphologies were found (see Fig. 2C). This observation indicates the occurrence of specific reaction of the fibre surfaces when free thiols are available, as well as some, albeit low-level, non-specific peptide interaction at the surface of the fibres with no thiols present.

\section{Cell expansion and phenotype support}

hCSCs were isolated from corneascleral rims as previously described ${ }^{23}$ and cultured on the fabricated scaffold (see protocol sup. Section 1). The media composition of DMEM/F12 with $20 \%$ serum replacement, fibroblast growth factor and leukaemia inhibitory factor (SCM) has previously reported to support the keratocyte phenotype of $\mathrm{hCSCs}^{23}$ and was therefore used in this study. Enhanced proliferation was observed on the scaffolds with an increased content of the laminin mimetic peptide sequence NorGGG-YIGSR compared to the PLA/PDEGMA scaffolds (Fig. 3A). Interestingly, significantly higher proliferation was also found on PLA with PDEGMA/PDEGSH in the fibres (Fig. 3A). Morphology staining (actin and vimentin for the cytoskeleton) studies showed clusters of cells on PLA, and PLA with 10 wt\% PDEGMA (OSH, Fig. 4 and S26), elongated cell morphologies on PLA with PDEGMA/PDEGSH (90:10, Fig. S26), and an increase in a spindle-like morphology of the cells on the peptide derivatised PLA scaffolds with more PDEGMA/PDEGS-Nor-GGG-YIGSR present (Fig. 4 and S26). The round morphology of the cells on the PLA, and PLA with 10 wt\% PDEGMA scaffolds indicated a limited interaction between the cells and the fibrous scaffold. This in turn suggested that protein deposition was not enhanced when the adhesion peptides were merely adsorbed (as detected by ToF-SIMS analysis) rather than being covalently bound to the fibre surface. The elongated morphologies of cells attached to the thiol-functionalised 
A

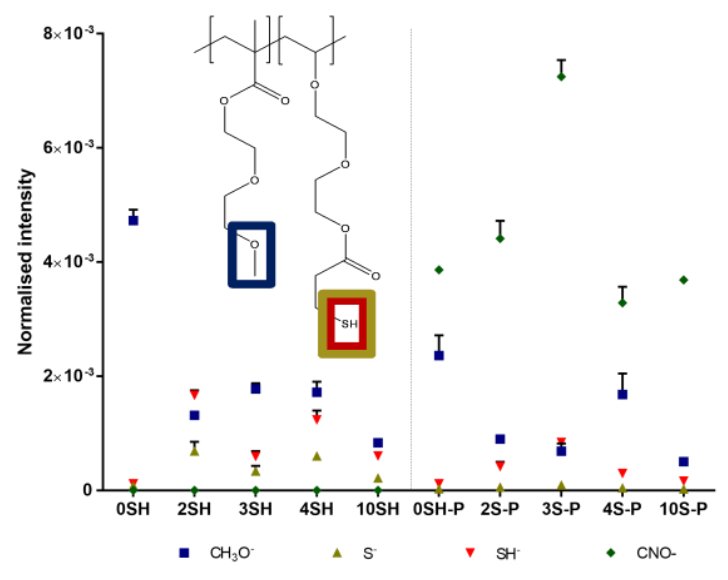

B

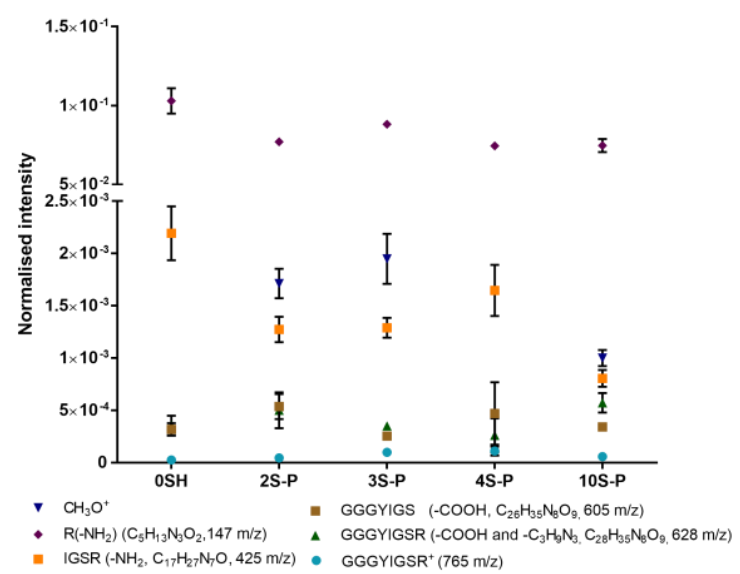

C
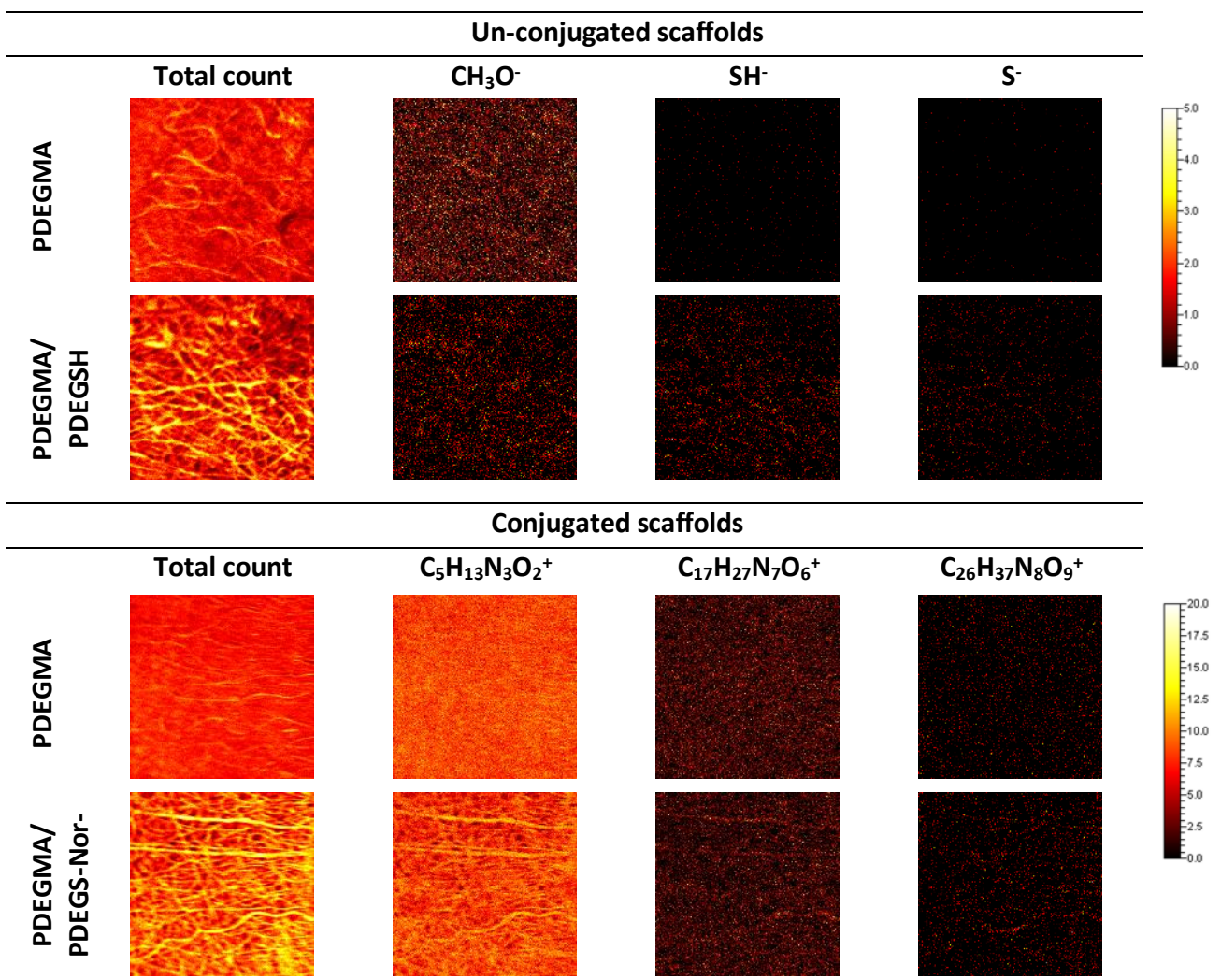

Figure 2. A) Total intensity of the ToF-SIMS peaks $\mathrm{CH}_{3} \mathrm{O}^{-}(31 \mathrm{~m} / \mathrm{z}), \mathrm{SH}^{-}(33 \mathrm{~m} / \mathrm{z})$ and $\mathrm{S}^{-}(32 \mathrm{~m} / \mathrm{z})$ from the free thiol containing scaffolds. B) Total intensity of different sequences of the Nor-GGG-YIGSR peptide presences on the scaffold surfaces, (R(- $\left.\mathrm{NH}_{2}, 147 \mathrm{~m} / \mathrm{z}\right), \mathrm{GSR}(-\mathrm{COOOH}, 326 \mathrm{~m} / \mathrm{z}), \mathrm{IGSR}\left(-\mathrm{NH} \mathrm{H}_{2}, 425 \mathrm{~m} / \mathrm{z}\right), \mathrm{GGGYIGS}(-\mathrm{COOH}, 605 \mathrm{~m} / \mathrm{z}), \mathrm{GGGYIGSR}(-\mathrm{COOH}$, $628 \mathrm{~m} / \mathrm{z}$ ) and GGGYIGSR(765 m/z). ( $\mathrm{n}=3$ measurements areas on one scaffold each, data normalised against total count, error bar =SD) C) ToF-SIMS signal intensity images.

scaffolds was due most probably to direct cell surface-thiol reactions, for example via surface exposed cysteines. This assertion is supported by prior data showing that thiolated surfaces can result in improved ECM protein adsorption and subsequently enhanced cell attachment and proliferation. ${ }^{24,25,26}$ However, significantly more cells exhibiting a spindle-like morphology were observed when the laminin mimetic sequence YIGSR was present (see Fig. 4). Uzunalli et al. ${ }^{15}$ reported a similar morphology of hCSCs when cultured on YIGSR-containing nanofibres compared to fibronectin-mimetic RGD-peptide nanofibres, as well as increased proliferation, supporting the findings reported here. 
A

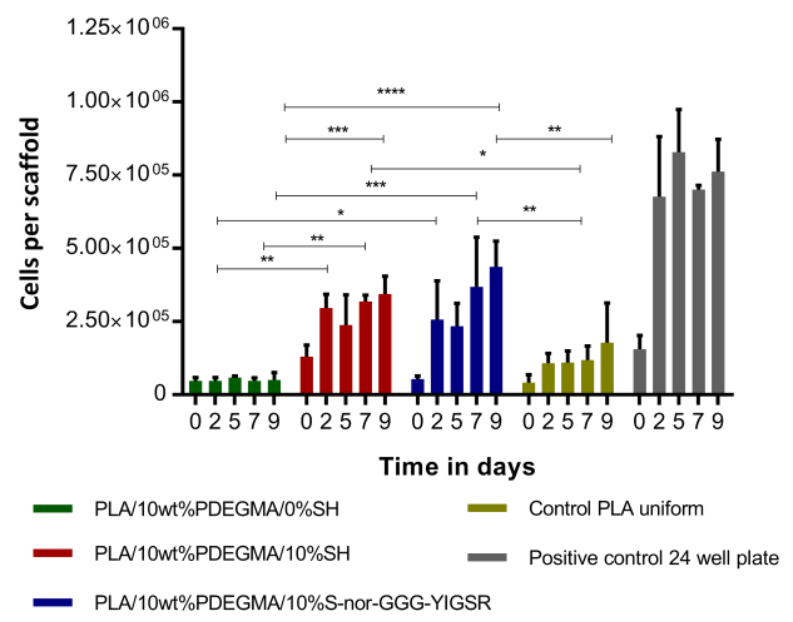

B

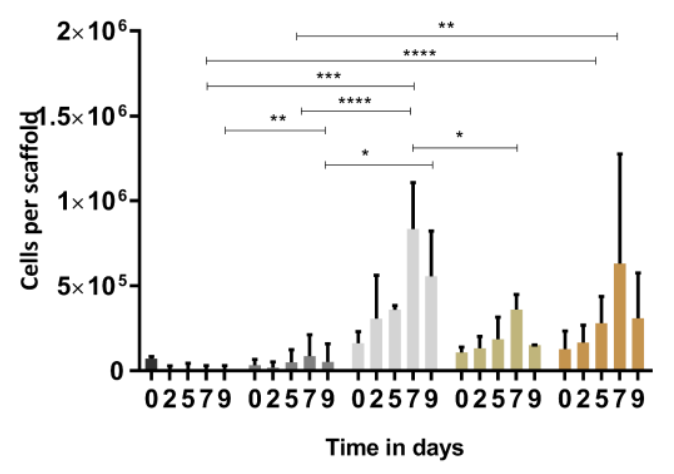

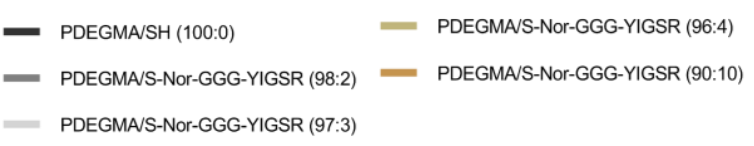

Figure 3. A) Cell proliferation on the different scaffolds types compared to control over 9 days of culture. B) Cell proliferation on the peptide derivatised scaffolds of different concentration over 9 days of culture.

Immuno-staining of the hCSCs showed the quiescent keratocyte phenotypic markers CD34 and ALDH, and mesenchymal stem cell (MSC) expression of CD105 on all the different scaffolds (see Fig. 4 and Fig. S26). In addition, the expression of myofibroblast marker $\alpha$-SMA was found when cells were cultured on the PLA and PLA with 10 wt\% PDEGMA scaffolds, and a very low expression of $\alpha$-SMA was also observed when cells were cultured on the PLA fibres with 10 wt\% PDEGMA/PDEGSH (90:10, Fig. S26). No $\alpha$ SMA expression was detected when cells were cultured on any of the PLA fibres functionalised with 10 wt\% PDEGMA/PDEGS-NorGGG-YIGSR. These data confirmed that the peptide supported the quiescent keratocyte phenotype and suppressed dedifferentiation of the keratocytes to their activated myofibroblast phenotype.

ECM expression was investigated to confirm the hypotheses that the free thiol group-containing scaffold supported ECM expression and adsorption and hence cell adhesion and proliferation as observed in Fig. S26. Collagen I expression was observed throughout all the scaffolds (Fig. 4), however, this protein increased in abundance and was more evenly distributed on the peptide containing scaffolds (Fig. 4). These results confirmed that PDEGMA/PDEGS-Nor-GGG-YIGSR peptide functionalisation on the scaffold led to an increased expression of collagen I. Stromal keratocytes in a normal undamaged cornea express the keratan sulphate proteoglycan, lumican, a corneal transparency factor. 27,28 Lumican interacts with collagen fibrils helping to maintain spacing and transparency in a healthy cornea ${ }^{29}$. Production is significantly reduced during wound healing and phenotypic change to a fibroblast morphology, and thus the presence of lumican can be considered a marker of the quiescent phenotype of hCSCs. As apparent from Figure 4, lumican expression was found on the scaffolds with peptide present, including the OSH scaffold with non-specific bound peptide. This indicated that the non-specifically bound Nor-GGG-YIGSR on the surface detected during ToFSIMS analysis did support ECM expression. However, myo-fibroblast differentiation and clusters of cells were still observed, suggesting that the non-specifically bound peptide did not support strong cell interactions with the scaffold. It was observed that cells spread out across the surfaces only when the peptide was covalently bound to the fibres. Increased lumican expression was detected for the peptide bound scaffolds with 3, 4 and 10\% PDEGSH attached, providing support for assertion (Fig. 4). As the derivatised scaffolds with the Nor-GGG-YIGSR peptide were observed to promote the desired quiescent phenotype, spindle-like morphology and ECM expression, the cellular responses on the surfaces with different percentages of peptides attached were investigated. After 9 days cell culture, significantly higher proliferation was observed for 3 and $10 \%$ peptide-derivatised scaffolds (Fig. 3B). The expression of the quiescent keratocyte phenotype CD34 and ALDH markers were detected for all different concentrations of peptide (Fig. 4). A significantly increased expression of ALDH was observed for the 3\% peptide scaffold. As ALDH expression plays an important role in the maintenance of corneal transparency, this indicated a desirable response of the cells in terms of their culture on the derivatised fibres. In addition, CD105 MSC marker expression was found on all scaffolds, suggestive of a partial loss of the differentiated quiescent phenotype to a more stem cell-like phenotype. ${ }^{30}$ Myo-fibroblastic $\alpha$-SMA expression was observed for those cells cultured on scaffolds containing $2 \%$ peptide and on the $0 \%$ control, indicating a threshold of peptide content needed to avoid myofibroblast activation. Peptide concentrations of $2 \%$ were too low to support the quiescent phenotype and resulted in a myo-fibroblastic change, while cells cultured on scaffolds containing $3 \%$ peptide and above generated no $\alpha$-SMA expression. The previously rounded and cluster cell morphology was observed on the scaffolds containing 0 and $2 \%$ peptide 


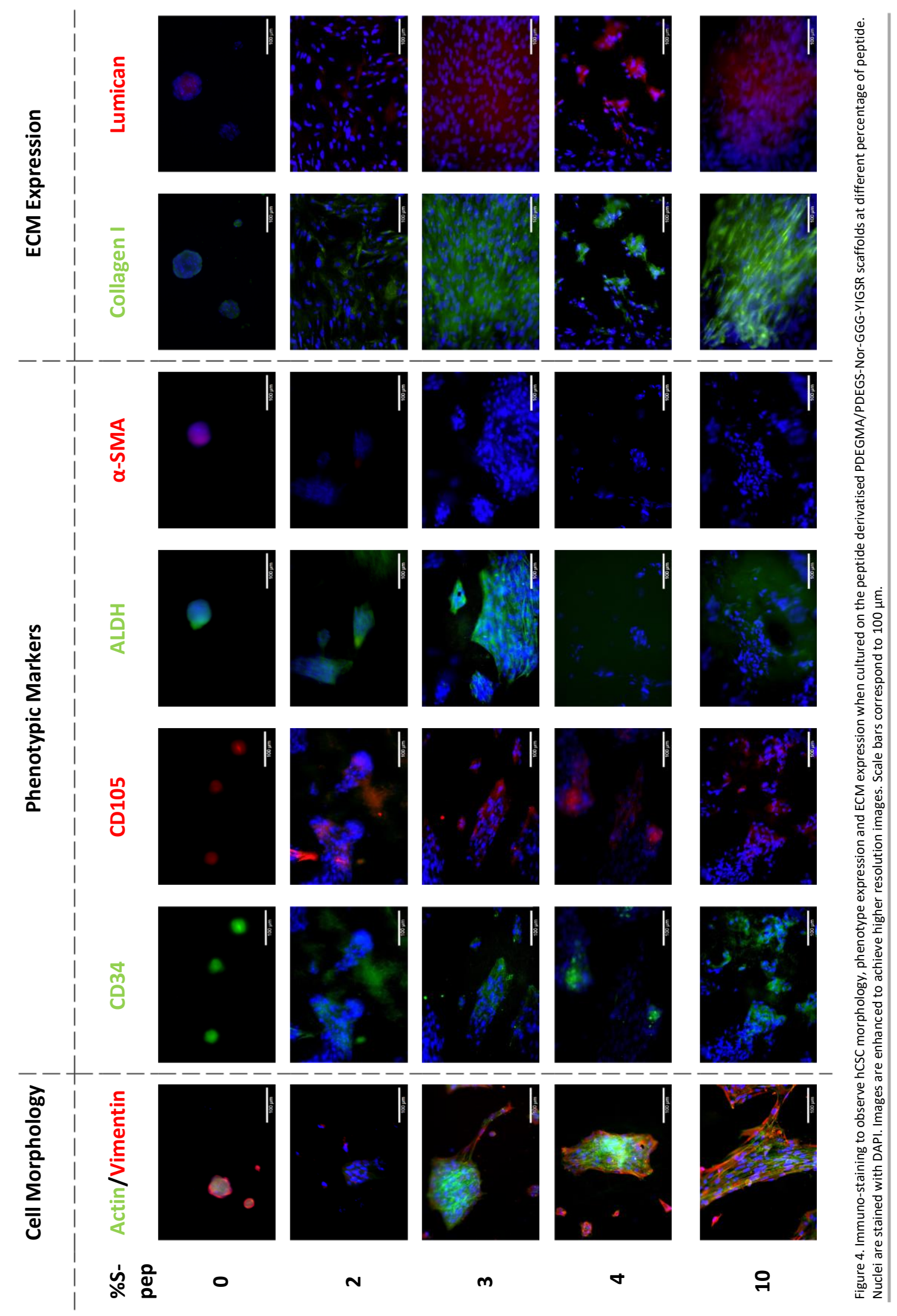


concentrations, while a more fusiform morphology was observed when cultured on scaffolds with peptide-concentrations above 2\% (Fig. 4). Moreover, lumican ECM expression was detected when cells were cultured on scaffolds with higher percentages of peptide on the surface $(3,4$, and $10 \%)$. It can therefore be concluded that scaffold fibres with more than $2 \%$ of Nor-GGG-YIGSR covalently bound to their surfaces significantly improved hCSCs attachment, proliferation, ECM expression and supported a quiescent cell phenotype.

\section{Enzymatic-free passaging}

The thermo-responsive PDEGMA/PDEGS-Nor-GGG-YIGSR polymer PLA scaffolds were not only designed to improve cell attachment and phenotype support, but also to prevent cell damage, which can occur through enzymatic passaging. Many studies to date have investigated the potential of the thermo-responsive polymer, PNIPAM, for corneal cell type detachment. ${ }^{8,31-33}$ We have recently shown that blend electrospinning a thermo-responsive polymer poly(PEGMA188) with a bulk polymer of choice will render the fibre thermo-responsive. Mammalian cell adhesion, viability, proliferation and phenotype on this fibrous culture system over numerous thermal enzyme-free passages was achieved. ${ }^{34}$ However, no other studies are reported to date utilising such thermo-responsive scaffolds for mammalian cell culture. A preliminary experiment illustrating the ability to culture and detach cells from PDEGMA and PDEGMA/PDEGS-Nor-GGG-YIGSR-containing scaffolds, and the subsequent quantitative assessment of the cell phenotype by flow cytometry analysis (FACS), was performed. hCSCs grown on peptide-derivatised fibrous scaffolds containing different concentrations of PDEGMA/PDEGS-Nor-GGG-YIGSR were passaged after 9 days of cell culture at $37^{\circ} \mathrm{C}$ by placing the scaffolds in the fridge for 30 mins at $4^{\circ} \mathrm{C}$ (section 1 supplementary data). Cell detachment was observed for all scaffolds with no significant difference in percentage of population detached (Fig. 5A). However, large standard deviations were observed for the scaffolds containing 2 and 10\% PDEGMA/PDEGS-Nor-GGG-YIGSR (Fig. 5A). This may have been due to heterogeneous cell attachment to the lowest percentage peptide derivatives (2\% PDEGS-Nor-GGG-YIGSR /PDEGMA) and very strong adhesion to the more extensively peptide-functionalised fibres (10\% PDEGS-Nor-GGG-YIGSR /PDEGMA). Nonetheless, more consistent cell detachment was observed for the scaffolds containing 3 and 4\% PDEGMA/PDEGS-Nor-GGG-YIGSR.

Flow cytometry analysis of cell surface markers of cells detached from the scaffolds was carried out to validate immuno-staining findings. Cells cultured on $3 \%$ peptide scaffolds were observed to have an increased sub-population of $16 \%$ of cells that only expressed the $\mathrm{CD} 34^{+} / \mathrm{CD} 105-$ keratocyte marker (Fig. 5B and Tab. S5-6) compared to those cultured all other scaffolds. However, $\mathrm{CD} 34 / \mathrm{CD}_{105}{ }^{+}$and $\mathrm{CD} 34^{+} / \mathrm{CD} 105^{+}$sub-populations combined constituted half of the total cell population (53\%, Tab. S5) whereas $\mathrm{CD} 4^{+} / \mathrm{CD} 105^{+}$and $\mathrm{CD} 34^{+} / \mathrm{CD} 105^{-}$cells comprised $45 \%$ of the total cell population. Therefore, a significant percentage of the population exhibited MSC characteristics besides those of the desired keratocyte CD34 marker. A similar sub-population percentage of $\mathrm{CD} 34-/ \mathrm{CD} 105^{+}$and $\mathrm{CD} 34^{+} / \mathrm{CD} 105^{+}$cells $(51 \%)$ was detected when cultured on the scaffolds with $4 \%$ peptide on the surface, nevertheless there was an increase in the proportion of cells which expressed the CD34 marker (38\% of total cell population, Tab. S5). Significantly less CD34+/CD $105^{+}$expression was observed for all scaffolds compared to the $2 \mathrm{D}$ TCPS control when comparing the Y-mean (Tab. S6). This observation shows that the 3D culture environment significantly reduced the expression of the MSC marker CD105 but no significant difference was seen for the different percentage content of peptides (Tab. S7-8). In addition, an increased expression of $\mathrm{ALDH}^{+} / \alpha-\mathrm{SMA}^{-}$was demonstrated when cells were cultured on 3 and $4 \%$ peptide scaffolds (Fig. 5C). In terms of the total cell population, 24, 28, 19 and 32\% (ALDH $+\alpha-\mathrm{SMA}^{-}$and ALDH ${ }^{+} / \alpha-\mathrm{SMA}^{-} \mathrm{Combined}^{-} \mathrm{Tab}^{-} \mathrm{S} 5$ ) for 2, 3, 4 and 10\% peptide-functionalised fibres, respectively, were shown to express the $\alpha$-SMA activated myofibroblastic marker. This was significantly less than the $93 \%$ observed for the 2D control. Hence, the 3D structure of the scaffolds containing covalently bound peptide on the surface reduced the differentiation to the undesired activated myo-fibroblastic phenotype compared to the 2D control. Although no significant difference could be observed between the scaffolds for CD34/CD105 expression, a significant decrease of $\mathrm{ALDH}^{-} / \alpha-\mathrm{SMA}^{+}$was seen for the scaffolds with 3 and $4 \%$ peptide compared to $2 \mathrm{D}$ and the adsorbed peptide scaffold when comparing the X-mean (Tab. S6-8). This gives an indication that the covalently attached peptide reduced the change to the activated myofibroblast phenotype and supported increased ALDH expression.

In general terms, these data were in accord with the improved results in 3D fibrous scaffolds for cell culture and tissue engineering compared to 2D cultures reported in recent years..$^{35-39}$ The fibrous structure in these materials was designed to mimic ECM properties, resulting in an increase in desired cell response. However, as the synthetic polymers used in our culture assays were non-native to the cells, we anticipated that peptide or protein incorporation or functionalisation would be required to overcome some key practical challenges. These included poor cell attachment and induction of inflammation or undesired cell differentiation due to the sub-optimal mechanical or chemical properties (such as stiffness and hydrophobicity) of conventional polymer fibres. ${ }^{35-}$ ${ }^{39}$ For example, Rodina et al. ${ }^{38}$ investigated migration and proliferation of mesenchymal stromal stem cells (MSSCs) on collagen protein modified PLA fibrous scaffolds. They observed more uniform distribution and cell penetration into these modified scaffolds. In addition to proteins, more specific peptide sequences can be used as ligands for enhanced cell attachment. The Arg-Gly-Asp (RGD) collagen peptide sequence is the most commonly used peptide incorporated in biomaterials to increase their cell adhesion properties. ${ }^{40}$ Besides, incorporation of known cell attachment peptide sequences (such as RGD), more cell specific peptide sequences can be incorporated to improve selective cell function or differentiation on the materials. ${ }^{41}$ Examples include the 
A

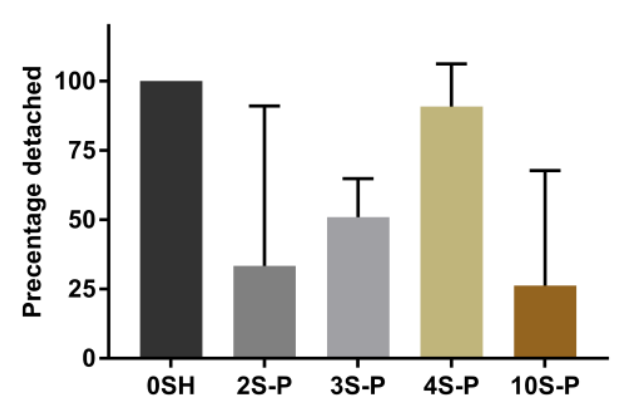

B

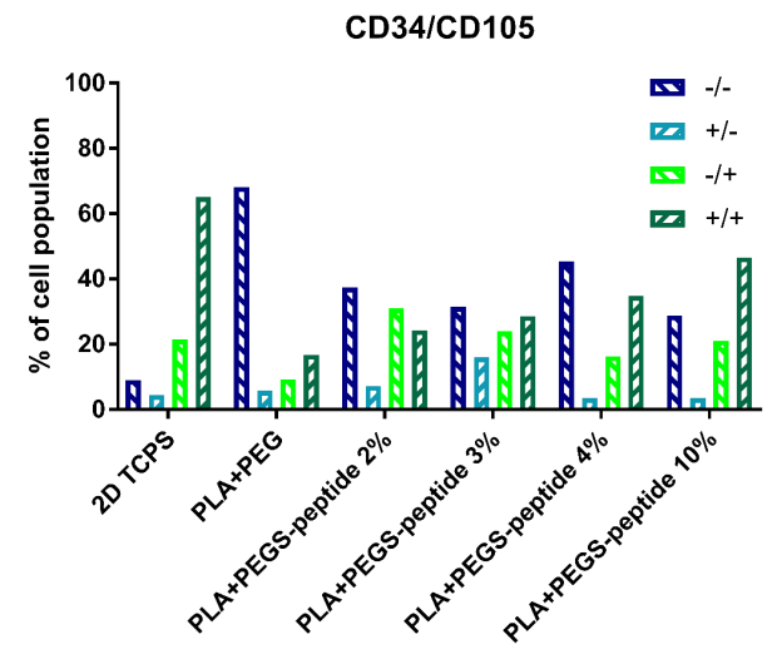

C

ALDH/ $\alpha$-SMA

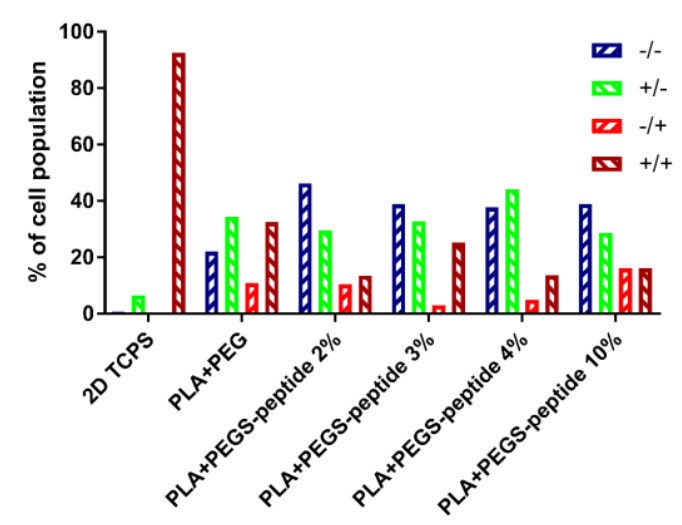

Figure 5. A) Percentage of cells detached after thermo-responsive passaging of the different concentrations of peptide on the surface. (n=3 scaffolds, two-way ANOVA, error bars=SD). B) Flow cytometry percentage of cell population expressing the desired keratocyte marker CD34 and/or mesenchymal stem cell marker CD105 after thermo-response detachment from the different scaffolds. ( $n=3$ cells detached from 3 scaffolds per scaffold type, control cell passage with trypsin from TCPS) $\mathrm{C}$ ) Flow cytometry percentage of cell population expressing the desired keratocyte marker ALDH and/or the undesired myo-fibroblastic marker $\alpha$-SMA after thermo-response detachment from the different scaffolds. ( $n=3$ cells detached from 3 scaffolds per scaffold type, control cell passage with trypsin from TCPS)

laminin-derived peptides IKVAV42 and YIGSR 43 for cell attachment and anti-cancerous response, specific bone morphogenetic protein-2-related peptide P24 and rhBMP $_{2}, 44,45$ and enzyme responsive peptides (such as Fmoc-propargyl-GAARGD, which can be cleaved to ARGD by the enzyme elastase expressed by porcine pancreas). ${ }^{46}$

In this study, we set out a new approach for 3D mammalian cell culture by functionalising thermo-responsive fibrous scaffolds with a cell responsive peptide sequence. The methodology employed here to functionalise the scaffolds is amenable to the attachment of other peptide sequences as desired. In our case the laminin-1 peptide component, YIGSR, known to promote hCSCs interaction and to support the quiescent keratocyte culture on the scaffolds was chosen as an exemplar. ${ }^{15}$

Previous studies have demonstrated that laminin improves growth, organisation and differentiation of many cell types. ${ }^{15,47-50}$ Nonetheless, the use of laminin has many disadvantages such as degradation in culture to inactive fragments, tumorigenesis and induction of immune-responses, which make the full sequence unsuitable for clinical application. ${ }^{51}$ This risk can be minimised by selecting small peptide sequences within the laminin structure, which have the ability to improve adhesion and cell migration. One of these sequences is YIGSR, which has been observed to improve cell adhesion and migration. ${ }^{52-54}$ For example, Uzunalli et al. ${ }^{15}$ investigated the response of hCSCs on bioactive self-assembled peptide nanofibres. Two peptide sequences were investigated; 1) YIGSR (laminin derived) and 2) RGD (fibronectin derived). In both these cases, hCSCs were observed to maintain their characteristic morphology, and their proliferation was enhanced when YIGSR was present. Significantly, less cell proliferation and adhesion was observed for the RGD fibres. This study suggested that the YIGSR sequence has a direct impact on hCSCs attachment, proliferation and migration on 3D structures. These observations are in line with the increase in proliferation observed of the hCSCs on our scaffolds with increasing ratio of GGG-YIGSR covalently bound on the surface. Many studies have reported improved attachment and proliferation of human cornea epithelial cells. ${ }^{55-59}$ However, only one paper has described the response of hCSCS on YIGSR 
incorporated scaffolds, ${ }^{15}$ and no phenotypic support study has been performed to our knowledge. The immuno-staining and flow cytometry data reported here suggests that not only does YIGSR enhance cell attachment and proliferation on the fibrous scaffold, but the peptide also supports a higher percentage of the cell population which expresses a quiescent phenotype. Down-regulation of the undesired myofibroblastic marker $\alpha$-SMA was detected, while up-regulation of keratocyte markers CD34 and ALDH was observed. Phenotypic characteristics were observed to remain constant when cultured and passaged, by the thermo-responsive enzymatic free passaging capabilities of the scaffolds. This gives an indication that such scaffolds can be designed to support the desired cell phenotype during in vitro culture and enzyme-free passaging and therefore this system is suitable for therapeutically relevant cell types.

\section{Conclusions}

The peptide functionalised, thermo-responsive electrospun scaffolds described here were designed for human cornea stromal cells (hCSCs) proliferation, phenotype support and enzymatic digestion-free passaging. The initially proposed scaffolds (PLA with 10 wt\% PDEGMA) did not facilitate hCSCs adhesion and proliferation. Therefore, a peptide-functionalised scaffold was produced to improve the attachment of hCSCs on the scaffold and support the desired quiescent phenotype. PDEGMA/PDEGSH polymers were accordingly synthesised, their thermo-responsive properties and thiol content confirmed, and the materials were successfully blend-electrospun with PLA into fibrous scaffolds. The presence and homogenous distribution of free thiol on the scaffold surfaces, and the subsequent conjugation of Nor-GGG-YIGSR was confirmed by ToF-SIMS analysis. Non-specific attachment of the peptide was observed on thermo-responsive fibres without free thiol functionality but microscopy studies showed aggregated cells on these scaffolds, while elongated and spread cell morphologies were observed on thiol-containing and covalently-bound peptide derivatised scaffolds. These data indicated that enhanced hCSCs interaction was dependent on covalent peptide-functionalisation of the thermo-responsive fibres. The undesired, activated myofibroblastic phenotype was observed to decrease with increased percentage of Nor-GGG-YIGSR conjugated polymers at the scaffold surface. The highest levels of peptide-functionalisation resulted in a decrease in keratocyte specific markers ALDH and CD34, whereas concentrations of 3 and 4\% Nor-GGG-YIGSR resulted in the highest expression of keratocyte markers, while suppressing the active myofibroblastic phenotype. Between $80-100 \%$ of cultured cells were observed to detach from the scaffolds at temperatures below the phase transition temperature of the thermoresponsive polymers at the surfaces of the fibres. Despite some variation in detachment of the cells from the scaffolds, cells were able to retain their cell phenotype after thermal cycles of attachment and detachment passaging. Hence, it can be concluded that the designed thermo-responsive peptide conjugate fibrous scaffolds are suitable for the attachment, proliferation, quiescent keratocyte phenotype support and temperature-mediated-passaging of hCSCs. In our studies, we used a sequence to aid in hCSCs cell culture and expansion, but the attached peptide sequence could easily be changed to select for a different cell type, making the fabricated scaffolds a versatile matrix for cell expansion and phenotype support of any cell type including those destined for the clinic.

\section{Acknowledgements}

This work was supported by the Engineering and Physical Sciences Research Council [grant number EP/F500491/ 1] in the EPSRC Centre of Doctoral Training in Regenerative Medicine. The authors would like to thank Jiang Long and David Scurr for the help in ToF-SIMS and Emily Smith and Marta Alvarez Paino for conducting the XPS measurements and analysis, as well as, Hang Lau, Tianzhi Luo and Michael Haider for their advice and help during the work conducted at the University of Delaware in Prof. Kristi Kiick, Prof. Pochan and Dr. Martin's labs.

\section{Notes and references}

1. $\quad$ K. Duval, H. Grover, L. H. Han, Y. Mou, A. F. Pegoraro, J. Fredberg and Z. Chen, Physiology, 2017, 32, $266-277$.

2. R. D. Xu, M. B. Taskin, M. Rubert, D. Seliktar, F. Besenbacher and M. L. Chen, Scientific Reports, $2015,5$.

3. C. M. Madl, S. C. Heilshorn and H. M. Blau, Nature, 2018, 557, 335-342.

4. S. Vedicherla and C. T. Buckley, Biomed Research International, 2017, DOI: 10.1155/2017/2395138.

5. H. L. Huang, H. W. Hsing, T. C. Lai, Y. W. Chen, T. R. Lee, H. T. Chan, P. C. Lyu, C. L. Wu, Y. C. Lu, S. T. Lin, C. W. Lin, C. H. Lai, H. T. Chang, H. C. Chou and H. L. Chan, Journal of Biomedical Science, 2010, 17.

6. P. Danhier, T. Copetti, G. De Preter, P. Leveque, O. Feron, B. F. Jordan, P. Sonveaux and B. Gallez, Plos One, $2013,8$.

7. F. Gambinossi, L. S. Sefcik, E. Wischerhoff, A. Laschewsky and J. K. Ferri, Acs Applied Materials \& Interfaces, $2015,7,2518-2528$.

8. S. Nara, S. Chameettachal, S. Midha, H. Singh, R. Tandon, S. Mohanty and S. Ghosh, Journal of Materials Chemistry B, 2015, 3, 4155-4169. 
K. Itoga and T. Okano, Journal of Materials Chemistry, 2010, 20, 8768-8775.

S. Dey, B. Kellam, M. R. Alexander, C. Alexander and F. R. A. J. Rose, Journal of Materials Chemistry, 2011, 21, 6883-6890.

X. Xue, L. Thiagarajan, S. Braim, B. R. Saunders, K. M. Shakesheff and C. Alexander, Journal of Materials Chemistry B, 2017, 5, 4926-4933.

A. Saeed, N. Francini, L. White, J. Dixon, T. Gould, H. Rashidi, R. C. Al Ghanami, V. Hruschka, H. Redl, B. R. Saunders, C. Alexander and K. M. Shakesheff, Advanced Materials, 2015, 27, 662-668.

S. A. Braim, K. M. Shakesheff, B. R. Saunders and C. Alexander, Journal of Materials Chemistry B, 2016, 4, $962-972$.

L. E. Sidney and A. Hopkinson, J Tissue Eng Regen Med, 2018, 12, e203-e215.

G. Uzunalli, Z. Soran, T. S. Erkal, Y. S. Dagdas, E. Dinc, A. M. Hondur, K. Bilgihan, B. Aydin, M. O. Guler and A. B. Tekinay, Acta Biomaterialia, 2014, 10, 1156-1166.

F. A. A. Ruiter, C. Alexander, F. Rose and J. I. Segal, Biomed Mater, 2017, 12, 055009.

P. Kingshott, S. McArthur, H. Thissen, D. G. Castner and H. J. Griesser, Biomaterials, 2002, 23, 4775-4785.

C. M. Mahoney, S. V. Roberson and G. Gillen, Analytical Chemistry, 2004, 76, 3199-3207.

D. Cossement, R. Gouttebaron, V. Cornet, P. Viville, M. Hecq and R. Lazzaroni, Applied Surface Science, 2006, 252, 6636-6639.

H. K. Shon, M. Son, K. M. Park, C. K. Rhee, N. W. Song, H. M. Park, D. W. Moon and T. G. Lee, Surface and Interface Analysis, 2011, 43.

Y. Yokoyama, S. Aoyagi, M. Fujii, J. Matsuo, J. S. Fletcher, N. P. Lockyer, J. C. Vickerman, M. K. Passarelli, R. Havelund and M. P. Seah, Analytical Chemistry, 2016, 88, 3592-3597.

M. Körsgen, A. Pelster, K. Dreisewerd and H. F. Arlinghaus, Journal of The American Society for Mass Spectrometry, 2016, 27, 277284.

L. E. Sidney, M. J. Branch, H. S. Dua and A. Hopkinson, Cytotherapy, 2015, 17, 1706-1722.

S. Y. Lee, C. Y. Ahn, J. Lee, J. H. Lee and J. H. Chang, Nanoscale Research Letters, 2012, 7, $279-285$.

P. Esmaeilzadeh, A. Kowitsch, F. Heyroth, G. Schmidt, S. Fischer, K. Richter and T. Groth, Carbohydrate Polymers, 2017, 157, 12051214.

K. Jans, B. Van Meerbergen, G. Reekmans, K. Bonroy, W. Annaert, G. Maes, Y. Engelborghs, G. Borghs and C. Bartic, Langmuir, 2009, 25, 4564-4570.

S. Ying, A. Shiraishi, C. W. Kao, R. L. Converse, J. L. Funderburgh, J. Swiergiel, M. R. Roth, G. W. Conrad and W. W. Kao, Journal of Biological Chemistry, 1997, 272, 30306-30313.

S. Saika, A. Shiraishi, C. Y. Liu, J. L. Funderburgh, C. W. C. Kao, R. L. Converse and W. W. Kao, Journal of Biological Chemistry, 2000, 275, 2607-2612.

K. Musselmann, B. Alexandrou, B. Kane and J. R. Hassell, J Biol Chem, 2005, 280, 32634-32639.

K. Hashmani, M. J. Branch, L. E. Sidney, P. S. Dhillon, M. Verma, O. D. Mclntosh, A. Hopkinson and H. S. Dua, Stem Cell Research \& Therapy, 2013, 4, 226-226.

K. Nishida, T. Okano and M. Yamato, Journal, 2005.

T. Sumide, K. Nishida, M. Yamato, T. Ide, Y. Hayashida, K. Watanabe, J. Yang, C. Kohno, A. Kikuchi, N. Maeda, H. Watanabe, T. Okano and Y. Tano, FASEB Journal: Official publication of the Federation of American Societies of Experimental Biology, 2006, 20, 392-394.

J. Teichmann, M. Nitschke, D. Pette, M. Valtink, S. Gramm, F. V. Hartel, T. Noll, R. H. W. Funk, K. Engelmann and C. Werner, Science and Technology of Advanced Materials, 2015, 16, 045003-045003.

A. M. Aladdad, M. H. Amer, L. Sidney, A. Hopkinson, L. J. White, C. Alexander and F. R. A. J. Rose, Acta Biomaterialia, 2019, DOI: https://doi.org/10.1016/j.actbio.2019.01.037.

N. Masoumi, D. Copper, P. Chen, A. Cubberley, K. Guo, R. Z. Lin, B. Ahmed, D. Martin, E. Aikawa, J. Melero-Martin and J. Mayer, Advanced Functional Materials, 2017, 27, 1606614-1606614.

J. M. Holzwarth and P. X. Ma, Journal of Materials Chemistry, 2011, 21, 10243-10251.

T. D. Stocco, B. V. M. Rodrigues, F. R. Marciano and A. O. Lobo, Materials Letters, 2017, 196, $221-224$.

A. V. Rodina, T. K. Tenchurin, V. P. Saprykin, A. D. Shepelev, V. G. Mamagulashvili, T. E. Grigor'ev, K. I. Lukanina, A. S. Orekhov, E. Y. Moskaleva and S. N. Chvalun, Bulletin of Experimental Biology and Medicine, 2016, 162, 120-126.

J. M. Lee, T. Chae, F. A. Sheikh, H. W. Ju, B. M. Moon, H. J. Park, Y. R. Park and C. H. Park, Materials Science and Engineering: C, 2016, 68, 758-767.

N. J. Hogrebe and K. J. Gooch, Journal of Biomedical Materials Research Part A, 2016, 104, 2356-2368.

N. Huettner, T. R. Dargaville and A. Forget, Trends in Biotechnology, 2018, 36, 372-383.

A. Farrukh, S. F. Zhao, J. I. Paez, A. Kavyanifar, M. Salierno, A. Cavalie and A. del Campo, Acs Applied Materials \& Interfaces, 2018, 10, 41129-41137.

L. M. Nibourg, E. Gelens, S. A. F. Nibourg, M. R. de Jong, R. Kuijer, T. G. van Kooten and S. A. Koopmans, Acta Ophthalmologica, 2016, 94, 721-729.

Z. H. Deng, Y. S. Li, X. Gao, G. H. Lei and J. Huard, Osteoarthritis and Cartilage, 2018, 26, $1153-1161$.

J. F. Li, L. Jin, M. B. Wang, S. B. Zhu and S. Y. Xu, Biomedical Materials, 2015, 10.

J. N. Roberts, J. K. Sahoo, L. E. McNamara, K. V. Burgess, J. L. Yang, E. V. Alakpa, H. J. Anderson, J. Hay, L. A. Turner, S. J. Yarwood, M. Zelzer, R. O. C. Oreffo, R. V. Ulijn and M. J. Dalby, ACS Nano, 2016, 10, 6667-6679.

A. M. Baur, T. I. Gamberger, H. G. Weerda, M. Gjuric and E. R. Tamm, Acta Otolaryngol, 1995, 115, 517-521.

K. Stamati, J. V. Priestley, V. Mudera and U. Cheema, Experimental Cell Research, 2014, 327, 68-77.

C. L. Maruyama, N. J. Leigh, J. W. Nelson, A. D. McCall, R. E. Mellas, P. Lei, S. T. Andreadis and O. J. Baker, Journal of Dental Research, 2015, 94, 1610-1617. 
50. C. V. Leiton, A. Aranmolate, C. Eyermann, M. J. Menezes, L. F. Escobar-Hoyos, S. Husain, S. J. Winder and H. Colognato, Journal of Neurochemistry, 2015, 135, 522-538.

51. P. Topley, D. C. Jenkins, E. A. Jessup and J. N. Stables, British Journal of Cancer, 1993, 67, 953-958-953-958.

52. Y. Hosokawa, Y. Takahashi, Y. Kadoya, S. N. M. Yamashina, Y. Yamada and H. Nogawa, Development, Growth \& Differentiation, 1999, 41, 207-216.

53. Y. Yamada, K. Hozumi, F. Katagiri, Y. Kikkawa and M. Nomizu, Biomaterials, 2013, 34, 6539-6547-6539-6547.

54. K. Nam, C. S. Wang, C. L. M. Maruyama, P. Lei, S. T. Andreadis and O. J. Baker, Journal of Dental Research, 2017, 96, 798-806.

55. K. Merrett, C. M. Griffith, Y. Deslandes, G. Pleizier and H. Sheardown, Journal of Biomaterials Science-Polymer Edition, 2001, 12, 647-671.

56. L. Aucoin, C. M. Griffith, G. Pleizier, Y. Deslandes and H. Sheardown, Journal of Biomaterials Science-Polymer Edition, 2002, 13, 447-462.

57. F. Li, D. Carlsson, C. Lohmann, E. Suuronen, S. Vascotto, K. Kobuch, H. Sheardown, R. Munger, M. Nakamura and M. Griffith, Proceedings of the National Academy of Sciences, 2003, 100, 15346-15351.

58. X. D. Duan, C. McLaughlin, M. Griffith and H. Sheardown, Biomaterials, 2007, 28, 78-88.

59. X. Duan and H. Sheardown, Journal of Biomaterials Science Polymer Edition, 2007, 18, 701-711. 